ORIGINAL PAPER

\title{
Hepatocellular carcinoma - Clinicopathological CHARACTERISTICS, SURVIVAL, AND EXPRESSION OF VARIOUS HISTOLOGIC MOLECULAR MARKERS
}

\author{
Dafina Nikolova ${ }^{1}$, Viktorija Chaloska Ivanova ${ }^{1}$, Magdalena Genadieva Dimitrova ${ }^{1}$, \\ Rubens Jovanovik ${ }^{2}$, Slavica Kostadinova Kunovska², Nikola Orovcanec 3 , \\ Gordana Petrushevska², Vesna Janevska²
}

\author{
${ }^{1}$ University Clinic for Gastroenterohepatology, Skopje, Republic of North Macedonia \\ ${ }^{2}$ Institute of Pathology, Faculty of Medicine, Skopje, Republic of North Macedonia \\ ${ }^{3}$ Department of Epidemiology and Biostatistics, Faculty of Medicine, Skopje, Republic of North Macedonia
}

\begin{abstract}
The aim of this study was to make a clinical characterisation of patients with hepatocellular carcinoma and to investigate the expression of a set of molecular markers in patients from the Republic of North Macedonia. We analysed 60 patients for clinicopathologic factors, and we investigated tumour tissue and surrounding liver tissue for immunoexpression of E-cadherin, $\beta$-catenin, cyclin D1, and p53. Infection with hepatitis virus $\mathrm{B}$ and $\mathrm{C}(\mathrm{p}<0.001)$, tumour dimension $(\mathrm{p}<0.001)$, vascular invasion $(\mathrm{p}<0.002)$, and tumour differentiation $(\mathrm{p}<0.021)$ significantly influenced the survival of the patients. E-cadherin and $\beta$-catenin expression reduction and cyclin D1 and $\mathrm{p} 53$ overexpression were significantly higher in the tumour than in the non-tumour tissue $(\mathrm{p}<0.001 ; \mathrm{p}<0.001 ; \mathrm{p}=0.001 ; \mathrm{p}<0.001$, respectively). No significant correlation was found between clinicopathological characteristics and the analysed molecules nor between the molecules themselves. The immunoexpression of E-cadherin, $\beta$-catenin, cyclin D1, and p53 was not related to the tumour aggressiveness and prognosis. However, their significantly higher expression in HCC tissue compared to that in non-tumour tissue indicate their important role in hepatocarcinogenesis. The clinicopathological characteristics of the neoplasm remain highly predictive factors for the survival of the patients.
\end{abstract}

Key words: hepatocellular carcinoma, clinicopathological features, survival, molecular markers.

\section{Introduction}

Hepatocellular carcinoma (HCC) is the most common primary cancer of the liver and one of the most common malignancies worldwide [1]. It is the third cause of cancer-related mortality [2]. Despite the considerable advancement in newly developed therapies, the overall mortality and morbidity for HCC are high, and the prognosis of patients remains poor $[3,4]$. Major risk factors for HCC include hep- atitis $\mathrm{B}$, hepatitis $\mathrm{C}$, chronic alcohol consumption, exposure to environmental toxins such as aflatoxin $\mathrm{B}$, and non-alcoholic fatty liver disease [5]. The incidence of HCC in different regions of the world varies due to the incidence of the risk factors.

In recent years significant progress has been made in understanding the pathogenesis and the molecular mechanisms of this disease. Many molecular markers have been shown to correlate with the 
invasiveness of HCC, and to have potential prognostic significance [6].

The aim of this study was to make clinical characterisation of patients with HCC and to correlate them with survival rates in patients from the Republic of North Macedonia. We also investigated the expression of a set of molecular histological markers for cell adhesion, proliferation, and cell cycle in samples of HCC and non-cancerous liver tissue, and we analysed their correlation with clinical characteristics and pathologic characteristics of the tumour.

\section{Material and methods}

We analysed 60 consecutive patients with histologically proven HCC, who were diagnosed and treated at the University Clinic of Gastroenterology and Hepatology and the University Clinic of Abdominal Surgery in Skopje from 2010 to 2016. Core biopsy specimens of 42 patients and operative material of 18 patients were analysed at the Institute of Pathology, Faculty of Medicine in Skopje. We used medical history files, ultrasound (US), computed tomography images (CT), and laboratory status from files, archive paraffin blocks, slides, and pathology reports. For ongoing patients we made the same examinations as for the retrospective group of 28 patients. We analysed the following clinical data: infection with hepatitis virus B and C, serum level of alpha-fetoprotein (AFP), chronic alcoholism, cirrhosis, multiplicity of tumour nodes, dimension of tumour node, and lymph node status. Hepatitis virus B and $\mathrm{C}$ infection were proven by ELISA tests for hepatitis B surface antigen, antibody to hepatitis B surface antigen, antibody to hepatitis B core antigen, hepatitis B envelope antigen, antibody to hepatitis B envelope antigen, and anti-HCV antibodies. AFP was quantitatively determined using a commercial ELISA (range in adults 0-10 ng/ml). Chronic alcoholism was defined as daily consumption of more than $60 \mathrm{~g}$ alcohol; cirrhosis was diagnosed by ultrasound and histologically confirmed. The presence of multiple or solitary tumour node and the dimensions of the nodes were confirmed by US or CT. In the operative material tumour nodes were additionally measured. The greatest dimension of a solitary node or the greatest dimension of the largest node in multiple tumour presentation was used as a parameter. Four groups of tumours with different dimensions were constructed: tumours $<3 \mathrm{~cm}, 3-5 \mathrm{~cm}, 5-10 \mathrm{~cm}$, and tumours with the greatest dimension $>10 \mathrm{~cm}$. Lymph node status was carried out by CT scan, and any lymph node with a diameter of more than $1 \mathrm{~cm}$ was considered to be enlarged. The stage of the disease was determined according to TNM classification [7]. The pathological characteristics that we analysed and microscopically obtained were: microvascular invasion and tumour grade (G1, G2, and G3) [8, 9]. New sections from the paraffin-embedded tissue with approx- imately equal parts of tumour tissue and surrounding liver tissue were made, and additional immunostainings were performed using avidin-biotin complex immunoperoxidase technique with antibodies against E-cadherin (Monoclonal mouse, Anti-Human, Clone NCH-38, Dako, dilution 1 : 200), $\beta$-Catenin (Monoclonal mouse, Anti-Human, Clone 17C2, Novocastra, dilution 1:200), Cyclin D1(Cyclin D1, Monoclonal Rabbit, Anti-Human, Clone EP12, Dako, dilution 1 : 100), and p53 (Monoclonal Mouse, Anti-Human, Clone DO-7, Dako, dilution 1 : 50) LSAB and EnVision kits from DAKO were used for the visualisation of the antigen-antibody reaction.

Two pathologists evaluated the slides separately in order to obtain objective findings for E-cadherin and $\beta$-catenin expression reduction and the cyclin D1 and p53 overexpression. Expression of E-cadherin and $\beta$-catenin was determined as a positive staining of the whole circumference of the hepatocyte membrane, and the reduction of the signal was determined as a loss of that signal partially or completely. The reduction was determined as an approximate percentage of signal loss in the whole tumour tissue sample on the slide at a magnification of $100 \times$, after previous analysis of the cell membranes at magnification $400 \times$. The immunoreactivity of the adjacent non-cancerous liver tissue was used as a referent immunostaining. Expression of cyclin D1 and p53 was evaluated as a positive nuclear staining. The percentage of positive nuclei was determined semi-quantitatively in the whole tumour tissue sample on the slide. The surrounding non-tumour liver tissue was evaluated in the same manner.

Correlations of the immunoexpression/reduction and the above-listed clinical and pathological parameters were made. The patients were followed up from the date of HCC diagnosis for 24 months.

For statistical analysis we used the statistical software package Statistica 7.1 for Windows and SPSS Statistics 23.0, applying: Descriptive Statistics, Mann-Whitney U Test, Kaplan Meier analysis (Log Rank (Mantel-Cox) \& Breslow test, Cox regression (Wald/Exp(B)/95.0\% CI for $\operatorname{Exp~(B)/(p)/Backward~}$ Stepwise \& Forward Stepwise, Spearman Rank Order $\mathrm{R}$, Multiple linear regression). Statistical significance was accepted when p-values $<0.05$.

All procedures performed in the study were done in accordance with the ethical standards of the institutional and/or national research committee and with the 1964 Helsinki declaration and its later amendments or comparable ethical standards.

\section{Results}

\section{Clinical profile of the patients}

Nineteen patients $(31.67 \%)$ out of 60 were female and $41(68.33 \%)$ were male, with age ranging from 
31 to 85 years, median $61.88 \pm 10.51$ years. Mean survival time for female patients was $8.86 \pm 1.76$ months, for males $13.03 \pm 1.50$ months, and overall survival was $11.61 \pm 1.19$ months.

Clinicopathological features of the analysed group are shown in Table I.

Infection with hepatitis $B$ and hepatitis $C$ viruses (HBV, HCV, respectively), dimension of the tumour, microvascular invasion, and tumour grade significantly influenced the survival of the patients with HCC (Table I, Fig. 1).

Cox proportional hazard regression model for survival analysis showed the most influential risk factor to the event was HCV infection ( $\mathrm{p}=0.002)$, followed by microvascular invasion ( $\mathrm{p}=0.03)$, the dimensions of tumour from 5 to $10 \mathrm{~cm}(\mathrm{p}=0.02)$, and tumour grade $(\mathrm{p}=0.04)$.

\section{Immunohistochemistry results}

E-cadherin and $\beta$-catenin: In both tumour and non-tumour areas hepatocytes showed moderate to strong membranous staining with weak cytoplasmic expression in a few cases. No nuclear staining with $\beta$-catenin antibody was detected in any of the analysed cases. Reduction of E-cadherin expression in

Table I. Clinicopathological features of patients and their tumours

\begin{tabular}{|c|c|c|c|c|}
\hline Parameter & No OF PATIENTS & $\%$ & $\begin{array}{c}\text { SURVIVAL MONTHS } \\
(\text { MEAN) }\end{array}$ & SigNifiCANCE (P) \\
\hline \multicolumn{5}{|l|}{ Hepatitis } \\
\hline No hepatitis & 18 & 30 & 11.17 & $0.005 * *$ \\
\hline $\mathrm{B}$ & 36 & 60 & 13.39 & $0.001 * *$ \\
\hline $\mathrm{C}$ & 6 & 10 & 2.83 & $0.001 * *$ \\
\hline \multicolumn{5}{|c|}{ Chronic alcoholism } \\
\hline No & 44 & 73.33 & 11.65 & N Sig \\
\hline Yes & 16 & 26.67 & 11.50 & N Sig \\
\hline \multicolumn{5}{|l|}{ Cirrhosis } \\
\hline No & 8 & 13.33 & 12.50 & N Sig \\
\hline Yes & 52 & 86.67 & 11.45 & N Sig \\
\hline \multicolumn{5}{|l|}{ Multiple nodes } \\
\hline Multiple & 20 & 33.33 & 12.81 & N Sig \\
\hline Single & 40 & 66.67 & 11.18 & N Sig \\
\hline \multicolumn{5}{|c|}{ Dimension of the tumour } \\
\hline$<3 \mathrm{~cm}$ & 9 & 15 & 11.96 & $0.02 *$ \\
\hline $3-5 \mathrm{~cm}$ & 10 & 16.67 & 21.67 & $0.02 *$ \\
\hline $5-10 \mathrm{~cm}$ & 26 & 43.33 & 8.42 & $0.001 * *$ \\
\hline$>10 \mathrm{~cm}$ & 15 & 25 & 10.67 & $0.01 *$ \\
\hline \multicolumn{5}{|c|}{ Enlarged lymph nodes } \\
\hline No & 54 & 90 & 11.85 & N Sig \\
\hline Yes & 6 & 10 & 9.33 & N Sig \\
\hline \multicolumn{5}{|l|}{ Vascular invasion } \\
\hline No & 22 & 36.67 & 16.82 & $0.002 * *$ \\
\hline Yes & 38 & 63.33 & 8.46 & \\
\hline \multicolumn{5}{|l|}{ Grade } \\
\hline G1 & 26 & 43.33 & 14.35 & $0.021 *$ \\
\hline G2 & 27 & 45 & 10.17 & \\
\hline G3 & 7 & 11.67 & 6.00 & \\
\hline \multirow[t]{2}{*}{ AFP } & Min & Max & Mean & - \\
\hline & 2.10 & 10,000 & 758.95 & N Sig \\
\hline
\end{tabular}

$p<0.05 * ; p<0.01 * *$ 
A

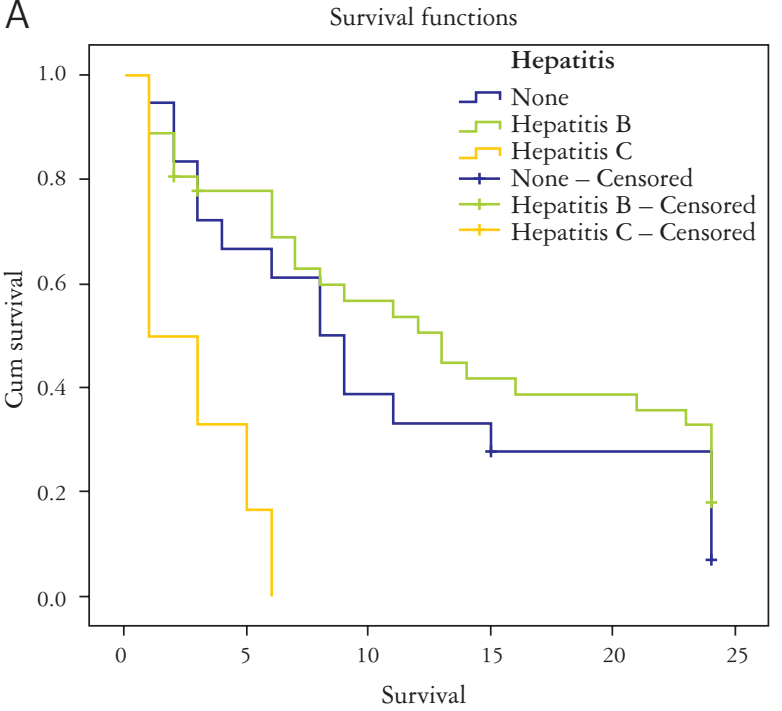

C

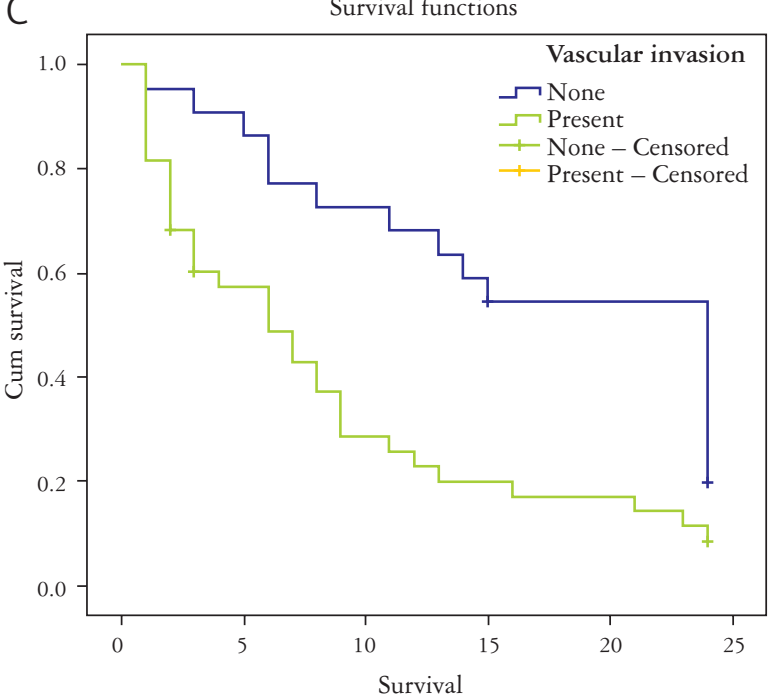

B

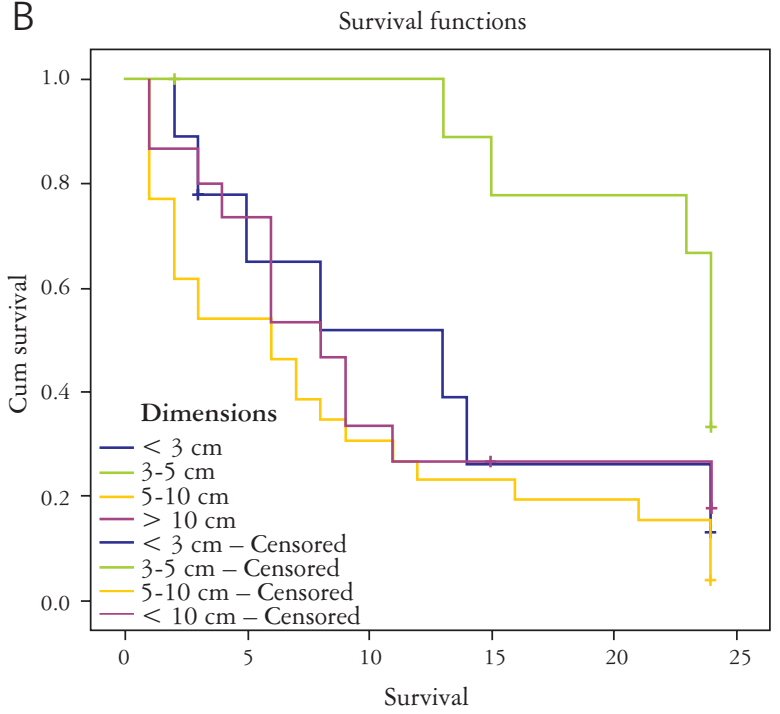

D

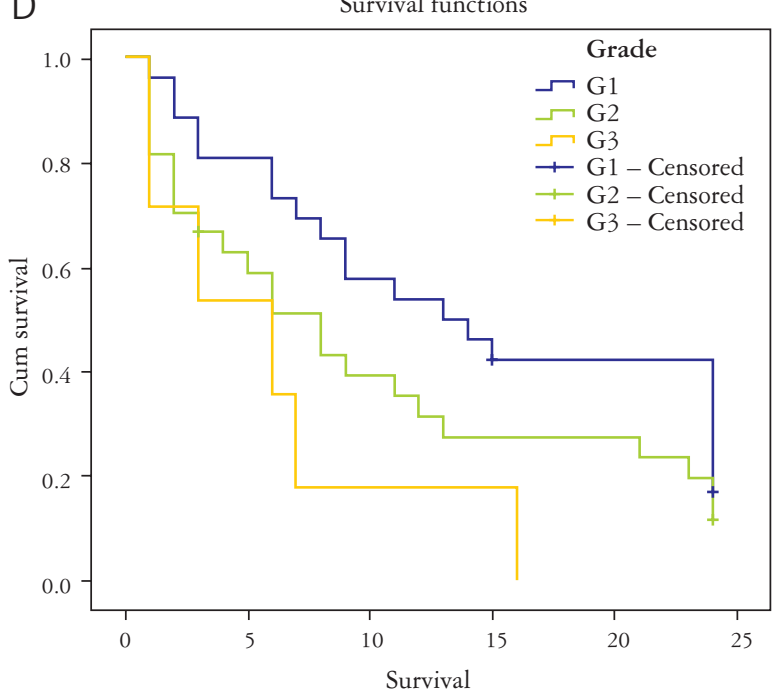

Fig. 1. Statistical difference in patients survival. Survival curves for the patients according to the: A) Hepatitis B and $\mathrm{C}$ virus infection; patients with HCC and hepatitis $\mathrm{C}$ virus infection had significantly shorter survival time in comparison to patients with hepatitis B virus infection $(p<0.01)$ and patients without hepatitis virus infection $(p<0.01)$; B) tumor dimension; patients with tumor dimensions $5-10 \mathrm{~cm}$ and $>10 \mathrm{~cm}$ had significantly shorter survival time in comparison to patients with tumor dimensions $3-5 \mathrm{~cm}(\mathrm{p}<0.01$ and 0.05 respectively); C) microvascular invasion; patients with microvascular invasion had shorter time of survival in comparison to patients without it $(\mathrm{p}<0.01)$; D) grade of differentiation; patients with G3 tumors had a shorter time of survival in comparison to patients with G1 and G2 tumors; the survival time was significantly shorter in patients with G3 tumors in comparison to patients with G1 tumors $(\mathrm{p}<0.05)$

non-tumour tissue was calculated from $0 \%$ to $20 \%$ (mean $7.57 \%$ ), and reduction of $\beta$-catenin expression was calculated from $0 \%$ to $60 \%$ (mean $15 \%$ ). Reduction of E-cadherin expression in tumour tissue was in the range from $5 \%$ to $90 \%$ (mean $42.62 \%$ ), and reduction of $\beta$-catenin expression in tumour tissue was in the range from $5 \%$ to $90 \%$ (mean $46.33 \%$ ).

Cyclin D1 and p53: Nuclear cyclin D1 immunoreactivity was observed in non-tumour liver tissue in the range from $0 \%$ to $20 \%$ (mean 7.86 ), and nuclear p53 immunoreactivity was calculated in range from $0 \%$ to $40 \%$ (mean 11.71 ). Nuclear cyclin D1 immunoreactivity in tumour tissue was in the range from $0 \%$ to $90 \%$ (mean $26.90 \%$ ), and nuclear p53 immunoreactivity was calculated in the range from $1 \%$ to $90 \%$ (mean $46.53 \%$ ). The intensity of signal was weak to strong.

Different patterns of reduction of membrane immunoreactivity of E-cadherin and $\beta$-catenin were seen, from focal to diffuse. The loss of the signal was seen in part of the membrane, whole membrane of a single cell, or whole membranes of clusters of cells (Fig. 2). 

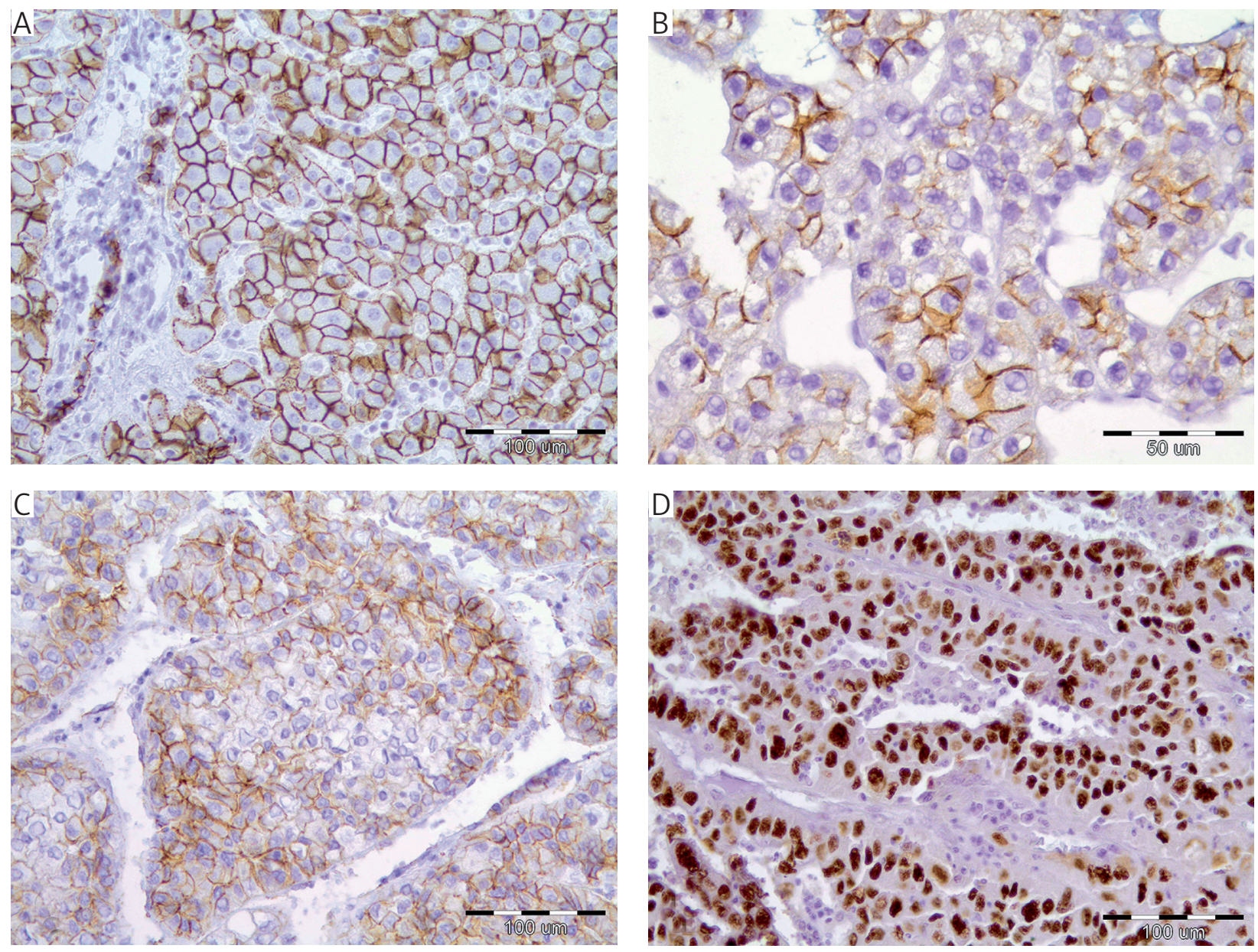

Fig. 2. Immunoexpression/reduction of the various analyzed molecules. A) E-Cadherin expression in a non-tumor liver tissue. Almost all hepatocytes in this microphotography show a strong membranous signal. The signal is week in some part of the membrane and it is disrupted in only few cells $(200 \times)$. B) Lost membrane expression of E-Cadherin in tumor tissue. E-Cadherin expression reduction is visible in most of the tumor cells. There is complete loss of the cell membrane signal in the vast majority of the cells in the microphotography but a proportion of the cells show some incomplete membranous expression $(400 \times)$. C) Reduction of $\beta$-catenin expression in tumor tissue - especially seen in the centre of the tumor lobule; the cells at the periphery of the lobule show incomplete membranous $\beta$-catenin expression $(200 \times)$. D) High percentage of $\mathrm{p} 53$ overexpression in tumor tissue. There is different signal intensity but the most of the cells in the microphotography show nuclear positivity for p53 $(200 \times)$. Immunohistochemical staining against E-cadherin $\mathrm{A}$ and $\mathrm{B}$; against $\beta$-catenin $-\mathrm{C}$; and against $\mathrm{p} 53-\mathrm{D}$ (brown color). Bar: um $=\mu \mathrm{m}$

\section{Correlations}

No significant correlation was detected between E-cadherin and $\beta$-catenin expression reduction, and cyclin D1 and p53 overexpression. Significant correlations in the expression of analysed molecules were found between the tumour tissue and non-tumour adjacent liver tissues. E-cadherin and $\beta$-catenin expression reduction and cyclin D1 and p53 overexpression were significantly higher in the tumour tissue $(\mathrm{p}<0.001 ; \mathrm{p}<0.001 ; \mathrm{p}=0.001 ; \mathrm{p}<0.001$, respectively) in comparison to the non-tumour tissue.

\section{Regression analysis}

Multiple linear regression analysis with E-cadherin as a dependent variable showed that the greatest influence to the reduction of E-cadherin expression was from tumour dimension $(5-10 \mathrm{~cm})$, followed by the level of serum AFP, HCV infection, enlarged lymph nodes, and microvascular invasion. In addition, with each increase in patient survival by one month, the reduction of E-cadherin expression decreased by $0.06 \%(\mathrm{~B}=-0.06 ; 95 \% \mathrm{CI}:-1.20$ to $1.08 ; \mathrm{p}>0.05)$, with unchanged values for other parameters. With $\mathrm{R}=0.43(\mathrm{~F}=0.79 ; \mathrm{p}=0.67)$ a moderately strong but not significant correlation was determined.

Multiple linear regression analysis with $\beta$-catenin as a dependent variable showed that tumour dimension $(5-10 \mathrm{~cm})$ had the greatest influence on the reduction of $\beta$-catenin expression, followed by microvascular invasion, the level of serum AFP, and enlarged lymph nodes, which had the least influence. With 
each increase in patient survival by one month, the reduction of $\beta$-catenin expression decreased by $0.40 \%$ $(\mathrm{B}=-0.40 ; 95 \% \mathrm{CI}:-1.43$ to 0.63$) ; \mathrm{p}>0.05)$, with unchanged values for other parameters. With $\mathrm{R}=0.54(\mathrm{~F}=1.48 ; \mathrm{p}=0.16)$ a moderately strong but not significant correlation was determined.

Microvascular invasion had the greatest influence on the expression of cyclin D1, followed by the level of serum AFP, HCV infection, and dimension of the tumour $(>10 \mathrm{~cm})$. With each increase in patient survival by one month, the expression of cyclin D1 decreased by $0.96 \%$ ( $\mathrm{B}=-0.96$; $95 \% \mathrm{CI}:-2.10$ to $0.19 ; \mathrm{p}>0.05)$, with unchanged values for other parameters. With $\mathrm{R}=0.44(\mathrm{~F}=0.81 ; \mathrm{p}=0.65)$ a moderately strong but not significant correlation was determined.

In descending order, the following factors had the greatest influence on the overexpression of $\mathrm{p} 53$ : dimension of the tumour $(5-10 \mathrm{~cm})$, microvascular invasion, level of serum AFP, enlarged lymph nodes, and finally HCV infection, which had the least influence. With each increase in patient survival by one month, the expression of p53 decreased by $0.46 \%$ $(\mathrm{B}=-0.46 ; 95 \% \mathrm{CI}:-1.70$ to $0.79 ; \mathrm{p}>0.05)$, with unchanged values for other parameters. With $\mathrm{R}=0.44(\mathrm{~F}=0.81 ; \mathrm{p}=0.64)$ a moderately strong but not significant correlation was determined.

The predictive values of E-cadherin, of $\beta$-catenin, cyclin D1, and p53 are shown in Table II.

We did not find significant influence of the immunoexpression of the E-cadherin, $\beta$-catenin (expression reduction), cyclin $\mathrm{D} 1$, and $\mathrm{p} 53$ (overexpression) on the survival of the patients $(p>0.05 ; p=0.92$; $\mathrm{p}=0.21 ; \mathrm{p}=0.21 ; \mathrm{p}=0.78$, respectively).

\section{Discussion}

\section{Clinicopathological characteristics}

With a median survival of eight months, and oneand three-year survival rates of $20 \%$ and $5 \%$, respectively, the effective treatment of HCC remains unsatisfactory. Better understanding of the pathogenesis of this disease, identification of molecular targets for therapeutic intervention, and availability of promising molecularly targeted therapies may give patients with HCC a chance for improved outcome [10, 11$]$. Information from different world regions are still needed to clarify not only geographic prevalence and aetiological factors, but also many other factors influencing HCC occurrence, in order to make better strategies in the treatment of HCC [12].

In this study we found HCC occurring in older population with a median age of $61.88 \pm 10.51$ years and with a male to female ratio of $2.15: 1$. According to the aetiological/risk factors, a total of $42 \mathrm{pa}-$ tients ( $70 \%$ of the patients) had HCC associated with hepatitis virus $B$ and hepatitis virus $C$ infection, and $86.67 \%$ of patients had HCC associated with cirrhosis (due to hepatitis virus $\mathrm{B}$ and $\mathrm{C}$ infection or alcoholism); only eight patients (13.33\%) had HCC in non-cirrhotic liver, all of them with histological changes in the liver tissue. The above-mentioned characteristics are similar to those reported in the literature over the last decades in patients from western countries $[1,5,13]$.

Most of the patients had a solitary tumour in the liver, and the dimensions of the tumour in most of the patients were $5-10 \mathrm{~cm}$ or over $10 \mathrm{~cm}$, which suggests a late stage at diagnosis. Enlarged lymph nodes were detected in only six $(10 \%)$ of the patients, while microvascular invasion was detected in $38(63.33 \%)$ patients. The most often reported grade was grade 2, found in 27 (45\%) patients, followed by G1 reported in $26(43.33 \%)$ patients.

Although most of the patients had well-differentiated and moderately-differentiated tumours, the median survival times were 13 and 8 months, respectively.

\section{Molecular markers}

A large number of genetic alterations and molecular factors have been shown to associate with the progression of HCC, and they have potential prognostic significance $[6,14]$. Understanding the molecular pathways in liver carcinogenesis and identification of molecules as targets for therapeutic intervention give hope for better prognosis of patients with HCC [11].

We chose to analyse E-cadherin and $\beta$-catenin molecules as components of Wnt signalling pathway,

Table II. Cox regression/survival and E-cadherin, $\beta$-catenin, cyclin D1, and p53

\begin{tabular}{lcccccccc}
\hline MoleCUle & \multicolumn{1}{c}{} & \multicolumn{1}{c}{ WE } & Wald & df & Sig. & Exp (B) & Lower & Upper \\
\hline E-cadherin & 0.001 & 0.005 & 0.01 & 1 & 0.92 & 1.001 & 0.990 & 1.011 \\
\hline B-catenin & 0.007 & 0.006 & 1.58 & 1 & 0.21 & 1.007 & 0.996 & 1.018 \\
\hline Cyclin D1 & 0.007 & 0.007 & 1.15 & 1 & 0.28 & 1.007 & 0.994 & 1.021 \\
\hline p53 & -0.002 & 0.006 & 0.08 & 1 & 0.78 & 0.998 & 0.987 & 1.010 \\
\hline
\end{tabular}


which is reported as one of the most important in the development of HCC. We also chose to analyse cyclin D1 as a target molecule of $\beta$-catenin as well as p53 as a protein with a key role in cell cycle regulation $[6,15,16]$.

E-cadherin is a single transmembrane domain glycoprotein mediating cell-cell adhesion. The cytoplasmic domain of E-cadherin is linked to the actin cytoskeleton through the catenins, including $\alpha$-catenin, $\beta$-catenin, $\gamma$-catenin, and $\mathrm{p} 120$, which strengthen cell-cell adhesion $[17,18]$. Besides the fundamental role $\beta$-catenin has regulating the E-cadherin-catenin cell adhesion complex, $\beta$-catenin also acts as a transcriptional activator of the Wnt signalling pathway and regulates transcription of target genes responsible for cell proliferation and differentiation [19-21]. Many authors have studied the genetic alteration of E-cadherin and $\beta$-catenin, their related pathways, and expression of E-cadherin and $\beta$-catenin molecules in various cancers including HCC [5, 14, 22, 23]. Reduced E-cadherin expression is associated with the progression of HCC, poor prognosis, poor differentiation, metastasis, and TNM stage $[17,21,24$, $25,26]$. Various immunoexpression of $\beta$-catenin is reported to be associated with tumour progression and development $[17,24]$.

In our study we did not find a statistically significant correlation between the reduction of $\mathrm{E}-\mathrm{cad}$ herin and $\beta$-catenin expression and the analysed clinicopathological parameters, although we found a tendency for greater reduction of E-cadherin and $\beta$-catenin expression to be in correlation with larger tumour mass, higher level of AFP, HCV infection, enlarged lymph nodes, microvascular invasion, and survival. We found that the expression of these two molecules was significantly different in tumour and non-tumour tissue, i.e. reduction of E-cadherin and $\beta$-catenin expression was significantly higher in tumour tissue, which indicates that both molecules may play a role in the carcinogenesis of HCC and may also play a role in tumour progression according to the tendency shown in relation to pathological parameters.

The cyclin family of proteins consists of cell cycle regulatory proteins [27]. Among the cyclins, the D-type (D1, D2, and D3) is the primary regulator of cellular progression and is required for cellular progression through the $G_{1}$ phase of the cell cycle $[28,29]$. Cyclin D1 is a major regulator of the progression of cells into the proliferative stage of the cell cycle, and it is a target molecule of Wnt signalling pathway [28]. Cyclin D1 protein overexpression has been reported in various human tumours, including HCC [29, 30]. Many authors suggest that increased expression of cyclin D1 may play an important role in the development of a subset of human HCC, and in experimental animals [31]. Some authors have found that overexpression of cyclin D1 shows relatively high sensitivity and specificity to predict worse outcome of HCC patients [32], but others have not found correlation between cyclin D1 expression and tumour cell proliferation [29] or tumour grade, survival rate, and any other clinicopathological parameters [33].

In our study we found negative correlation between E-cadherin and cyclin D1, i.e. higher expression of E-cadherin was associated with decrease of cyclin D1 expression, but insignificantly ( $p>0.05)$. $\beta$-catenin expression was negatively correlated with the expression of cyclin D1, but also insignificantly ( $p>0.05)$. Cyclin D1 expression in HCC tissue was significantly higher in comparison to non-tumour liver tissue ( $p=0.001)$, which suggests that cyclin D1 plays a role in HCC tumourigenesis and possibly in tumour progression based on the tendency shown regarding clinicopathological parameters.

p53 protein plays an essential role in cell-cycle arrest and cell death in response to DNA damage [5]. The wild type p53 protein is responsible for cell cycle regulation and apoptosis in a setting of DNA damage, while mutant $\mathrm{p} 53$ protein loses these functions $[34,35]$. The transition from wild type $\mathrm{p} 53$ to a mutant phenotype results in mutant p 53 protein accumulation and overexpression in the cell nuclei of cancer tissues [36]. Many authors have reported that p53 mutation was correlated with the tumour differentiation, the proliferating activity, tumour progression, and the invasiveness of HCC [5]. We did not find significant correlation between the expression of p53 and the analysed clinicopathological parameters in our study. A tendency for a higher percentage of stained nuclei to be in positive correlation with tumour dimension, microvascular invasion, level of serum AFP, survival of patients, enlarged lymph nodes, and HCV infection was present, but it was not statistically significant. We found a significantly higher percentage of positive nuclei in tumourous tissue compared to non-tumour tissue, which suggests that the p53 protein plays a role in HCC carcinogenesis.

In summary, our study showed that infection with $\mathrm{HBV}$ and $\mathrm{HCV}$, tumour dimension, and microvascular invasion in patients with HCC correlate with survival. The immunoexpression of E-cadherin, $\beta$-catenin, cyclin D1, and p53 was not apparently related to the tumour invasiveness/aggressiveness and prognosis, but their expression was significantly higher in HCC tissue than in non-tumour liver tissue, which suggests their important role in the tumourigenesis of HCC.

Data collected from many studies from different world regions may serve as a base for better understanding of clinical and pathological characteristics of HCC. The better understanding of the molecular mechanisms and pathogenesis of the disease leads to 
identification of molecular targets for therapeutic intervention and availability of promising molecularly targeted therapies $[10,11]$.

We would like to thank the University Clinic for Gastroenterohepatology and the Institute of Pathology in Skopje for supporting this study, and we thank the staff from both institutions for their help during the execution of this study. The authors declare no conflict of interest.

\section{References}

1. El-Serag HB. Hepatocellular carcinoma. N Engl J Med 2011; 365: 1118-1127.

2. Parkin DM, Bray F, Ferlay J, et al. Global cancer statistics 2002. CA Cancer J Clin 2005; 55: 74-108.

3. Altekruse SF, Henley SJ, Cucinelli JE, et al. Changing hepatocellular carcinoma incidence and liver cancer mortality rates in the United States. Am J Gastroenterol 2014; 109: 542-553.

4. Huang W, You L, Yang S, et al. S-1 for treatment of advanced hepatocellular carcinoma: a systematic review of the literature. Contemp Oncol (Pozn) 2017; 21: 16-20.

5. El-Serag HB, Rudolph KL. Hepatocellular carcinoma: epidemiology and molecular carcinogenesis. Gastroenterology 2007; 132: 2557-2576.

6. Qin LX, Tang ZY. The prognostic molecular markers in hepatocellular carcinoma. World J Gastroenterol 2002; 8: 385-392.

7. AJCC cancer staging manual. $8^{\text {th }}$ edition. Amin MB, Edge SB, Green F, et al. (eds). Springer, Switzerland 2017.

8. Hirohashi S, Ishak KG, Kojiro M, et al. Tumours of the liver and intrahepatic bile ducts. In: WHO classification of tumours of the digestive system. Hamilton S, Aaltonen LA (eds). $4^{\text {th }}$ ed. IARCPress, Lyon, France 2010; 195-263.

9. Schlageter M, Terracciano LM, D'Angelo S, et al. Histopathology of hepatocellular carcinoma. World J Gastroenterol 2014; 20: $15955-15964$.

10. Ng I. Molecular pathogenesis of hepatocellular carcinoma. Hong Kong J Radiol 2012; 15 (Suppl): S23-S28.

11. Terry K, Copur SM. Molecular targeted therapy of hepatocellular carcinoma. JCT 2013; 4: 426-439.

12. Sanyal AJ, Yoon SK, Lencioni R. The etiology of hepatocellular carcinoma and consequences for treatment. Oncologist 2010; 15 (suppl 4): 14-22.

13. Anzola M. Hepatocellular carcinoma: role of hepatitis B and hepatitis $\mathrm{C}$ viruses proteins in hepatocarcinogenesis. J Viral Hepat 2004; 11: 383-393.

14. Avadanei E, Giusca S, Negura L, Caruntu I. Single nucleotide polymorphisms of XRCC3 gene in hepatocellular carcinoma relationship with clinicopathological features. Pol J Pathol 2018; 69: 73-78.

15. Whittaker S, Marais R, Zhu AX. The role of signaling pathways in the development and treatment of hepatocellular carcinoma. Oncogene 2010; 29: 4989-5005.

16. Kasprzak A, Rogacki K, Adamek A, et al. Tissue expression of $\beta$-catenin and $\mathrm{E}$ - and $\mathrm{N}$-cadherins in chronic hepatitis $\mathrm{C}$ and hepatocellular carcinoma. Arch Med Sci 2017; 13: 1269-1280.

17. Zhai B, Yan HX, Liu SQ, et al. Reduced expression of E-cadherin/catenins complex in hepatocellular carcinomas. World J Gastroenterol 2008; 14: 5665-5673.

18. Yap AS. The morphogenetic role of cadherin cell adhesion molecules in human cancer: a thematic review. Cancer Invest 1998; 16: 252-261.

19. Nelson WJ, Nusse R. Convergence of Wnt, beta-catenin, and cadherin pathways. Science 2004; 303: 1483-1487.
20. Kemler R. From cadherins to catenins: cytoplasmic protein interactions and regulation of cell adhesion. Trends Genet 1993; 9: 317-321.

21. Wei Y, Van Nhieu JT, Prigent S, et al. Altered expression of E-cadherin in hepatocellular carcinoma: correlations with genetic alterations, beta-catenin expression, and clinical features. Hepatology 2002; 36: 692-701.

22. Huang H, Fujii H, Sankila A, et al. $\beta$-Catenin mutations are frequent in human hepatocellular carcinoma associated with hepatitis C virus infection. Am J Pathol 1999; 155: 1795-1801.

23. Polakis P. Wnt signaling and cancer. Genes Dev 2000; 14: 1837-1851.

24. Inagawa S, Itabashi M, Adachi S, et al. Expression and prognostic roles of beta-catenin in hepatocellular carcinoma: correlation with tumor progression and postoperative survival. Clin Cancer Res 2002; 8: 450-456.

25. Chen J, Zhao J, Ma R, et al. Prognostic significance of E-cadherin expression in hepatocellular carcinoma: a meta-analysis. PLoS ONE 2014; 9: e103952.

26. Endo K, Ueda T, Ueyama J, et al. Immunoreactive E-cadherin, alpha-catenin, beta-catenin, and gamma-catenin proteins in hepatocellular carcinoma: relationships with tumor grade, clinicopathologic parameters, and patients' survival. Hum Pathol 2000; 31: 558-565.

27. Kato J, Matsushime H, Hiebert SW, et al. Direct binding of cyclin $\mathrm{D}$ to the retinoblastoma gene product $(\mathrm{pRb})$ and $\mathrm{pRb}$ phosphorylation by the cyclin $\mathrm{D}$-dependent kinase CDK4. Genes Dev 1993; 7: 331-342.

28. Shtutman M, Zhurinsky J, Simcha I, et al. The cyclin D1 gene is a target of the beta-catenin/LEF-1 pathway. Proc Natl Acad Sci USA 1999; 96: 5522-5527.

29. Lim SC, Lee MS. Significance of E-cadherin/beta-catenin complex and cyclin D1 in breast cancer. Oncol Rep 2002; 9: 915-928.

30. Ueta T, Ikeguchi M, Hirooka Y, et al. Beta-catenin and cyclin D1 expression in human hepatocellular carcinoma. Oncol Rep 2002; 9: 1197-1203.

31. Deane NG, Parker MA, Aramandla R, et al. Hepatocellular carcinoma results from chronic cyclin D1 overexpression in transgenic mice. Cancer Res 2001; 61: 5389-5395.

32. Qu K, Wang Z, Fan H, et al. MCM7 promotes cancer progression through cyclin D1-dependent signaling and serves as a prognostic marker for patients with hepatocellular carcinoma. Cell Death Dis 2017; 8: e2603.

33. Lu JW, Lin, YM, Chang JG, et al. Clinical implications of deregulated CDK4 and Cyclin D1 expression in patients with human hepatocellular carcinoma. Med Oncol 2013; 30: 379.

34. Qi LN, Bai T, Chen ZS, et al. The p53 mutation spectrum in hepatocellular carcinoma from Guangxi, China: role of chronic hepatitis B virus infection and aflatoxin B1 exposure. Liver Int 2015; 35: 999-1009.

35. Jablkowski M, Bocian A, Bialkowska J, et al. A comparative study of P53/MDM2 genes alterations and P53/MDM2 proteins immunoreactivity in liver cirrhosis and hepatocellular carcinoma. J Exp Clin Cancer Res 2005; 24: 117-125.

36. Midgley CA, Lane DP. p 53 protein stability in tumour cells is not determined by mutation but is dependent on $\mathrm{Mdm} 2$ binding. Oncogene 1997; 15: 1179-1189.

\section{Address for correspondence}

\section{Dafina Nikolova}

University Clinic for Gastroenterohepatology

Vodnjanska bb, 1000 Skopje

Republic of Macedonia

e-mail: dafina.janevska@gmail.com 